\title{
Impacto da corticoterapia no equilíbrio ácido-básico de cabritos prematuros
}

Francisco Leydson Formiga Feitosa', Luis Gustavo Narciso, Juliane Teramachi Trevizan, Eva Liliane Dos Santos Silva, Jefferson Filgueira Alcindo, Fernanda Bovino, Dielson da Silva Vieira, Marcela Da Coll De Camargo, Maria Carolina Eugênia Facion, Luiz Cláudio Nogueira Mendes

Faculdade de Medicina Veterinária, Universidade Estadual Paulista (UNESP), Araçatuba, SP, Brasil

*Autor correspondente

e-mail: leydsonf@fmva.unesp.br

\section{Resumo}

Este trabalho teve como objetivo avaliar o impacto da corticoterapia no equilíbrio ácido-básico $\left(\mathrm{ph}, \mathrm{HCO}_{3}\right.$, $\mathrm{pCO}_{2}$ ) de cabritos no momento do nascimento (M0), 24 horas (M24) e 48 horas após o nascimento (M48) em diferentes protocolos. Foram utilizados 21 cabritos prematuros com, aproximadamente, 141 dias de gestação, oriundos de cesarianas em cabras submetidas a diferentes protocolos de corticoterapia (intramuscular), a saber: Grupo I - composto por sete cabritos utilizando a dosagem de 2 mg de dexametasona, dos 133 aos 136 dias, 4 mg dos 137 aos 138, e 20 mg aos 139 dias de prenhez; Grupo II - constituído por sete cabritos, com dosagem de $16 \mathrm{mg}$ de dexametasona aos 139 dias, com doses repetidas a cada 12 horas até a cirurgia eletiva; e Grupo III - composto por sete cabritos utilizando a dose de 4, 8, 16 e 20 mg de dexametasona, por via IM/SID, aos 137, 138, 139, 140 dias de gestação, respectivamente. A média obtida nos diferentes momentos para pH no Grupo I foram de 7,19 (M0), 7,40 (M24) e 7,35 (M48); no grupo II, 7,24 (M0), 7,38 (M24) e 6,12 (M48); e, no grupo III, 7,23 (M0), 7,39 (M24) e 7,35 (M48). Já os valores de HCO3 no grupo I foram de 23,15 (M0); 26,22 (M24) e 24,32 (M48); grupo II, 24,02 (M0), 29,73 (M24), e 21,10 (M48); e, grupo III, 24,84 (M0), 27,16 (M24) e 26,24 (M48). Os valores do PCO2 foram os seguintes: grupo I, 57,17 (M0), 38,73 (M24) e 40,20 (M48); grupo II, 55,97 (M0), 50,85 (M24), 38,97 (M48); e grupo III, 60,20 (M0), 45,14 (M24) e 47,14 (M48). Após a análise estatística, observou-se as seguintes alterações: $\mathrm{HCO}_{3}$, nos grupos I $(\mathrm{P}=0,0357)$ e II ( $\mathrm{P}=0,0078)$ houve diferença entre o M0 e o M24, além do grupo II apresentar diferença entre o M24 e o M48. Em relação ao pH, houve alteração no grupo I (P = 0,0012) e III $(P=0,0045)$, ocorrendo

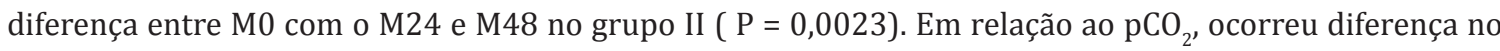
grupo III (P = 0,0033) entre o M0 com o M24 e o M48; não observou-se diferença estatística nos demais grupos. Portanto, conclui-se que ao nascimento a maioria dos cabritos apresentou acidose respiratória, acompanhada de aumento compensatório de $\mathrm{HCO}_{3}$ em alguns animais, provavelmente devido à retenção renal, tendendoo essas alterações a se normalizarem com o avançar das horas. 